\title{
COVID-19 and its effect on emergency presentations to a tertiary hospital with self-harm in Ireland
}

\author{
A. McIntyre ${ }^{1}$, K. Tong ${ }^{1}$, E. McMahon ${ }^{1}$ and A. M. Doherty ${ }^{2,3, *}$ (D) \\ ${ }^{1}$ Department of Psychiatry, University Hospital Galway, Galway, Ireland \\ 2 University College Dublin, Dublin, Ireland \\ ${ }^{3}$ Mater Misericordiae University Hospital Dublin, Ireland
}

Objectives: This study aimed to assess the impact of COVID-19 on presentations to an acute hospital with self-harm.

Methods: All presentations to University Hospital Galway with self-harm were assessed during the peak period of the coronavirus crisis in Ireland, over the 3 months from 1 March to 31 May 2020. These data were compared with presentations in the same months in the 3 years preceding (2017-2019). Data were obtained from the anonymised service database.

Results: This study found that in 2020, the rate of presentation with self-harm dropped by $35 \%$ from March to April and rose by $104 \%$ from April to May, peaking from mid-May. When trends over a 4-year period were examined, there was a significantly higher lethality of attempt $(p<0.001)$, and significant differences in diagnosis $(p=0.031)$ in 2020 in comparison with the three previous years. The increased lethality of presentations remained significant after age and gender were controlled for $(p=0.036)$. There were also significant differences in the underlying psychiatric diagnoses $(p=0.018)$, notably with a significant increase in substance misuse disorders presenting during the 2020 study period.

Conclusions: COVID-19 showed a reduction in self-harm presentations initially, followed by a sharp increase in May 2020. If a period of economic instability follows as predicted, it is likely that this will further impact the mental health of the population, along with rates of self-harm and suicidal behaviours. There is a need for research into the longer-term effect of COVID-19 and lockdown restrictions, especially with respect to self-harm.

Received 13 June 2020; Revised 27 August 2020; Accepted 21 September 2020; First published online 30 September 2020

Key words: Self-harm, self-injurious behaviour, suicide, attempted, COVID-19, psychiatry.

\section{Introduction}

In December 2019, the World Health Organisation (WHO) became aware of a novel coronavirus associated with atypical cases of pneumonia: severe acute respiratory syndrome coronavirus 2 (SARS-CoV-2), in Wuhan, China. This disease, COVID-19 has since then spread internationally and was declared a pandemic by the WHO on 11 March 2020. By 12 June 2020, there were 7633217 cases worldwide and 424495 deaths. COVID-19 is a highly infectious disease with direct neuropsychiatric effects, which are becoming increasingly recognised, along with the effects of the host immunologic response (Rogers et al. 2020). There are also however, secondary effects on mental health: these are the indirect effects of the virus on the mental health of the public through its broader societal impact, most notably in the quarantine and physical distancing requirements.

*Address for correspondence: A. M. Doherty, Consultant Liaison Psychiatrist, UCD/Mater Misericordiae University Hospital, 63 Eccles Street, Dublin 7, Ireland.

(Email: anne.doherty@ucd.ie)
Mental health services have also been required to reconfigure services in order to minimise the spread of coronavirus. People with severe mental illness (SMI) and those with personality disorders are known to have higher rates of physical health co-morbidity than the general population (Prince et al. 2007; Fok et al. 2012; Chesney et al. 2014; Walker et al. 2015). As a result of their increased rates of medical co-morbidity, they might be considered an at-risk group for poorer outcomes, should they contract COVID-19 (Kozloff et al. 2020). Furthermore, symptoms in SMI including positive symptoms, cognitive impairment and poor insight may impair the ability of people with SMI to follow public health advice, thus increasing their risk of infection (Maguire et al. 2019). Poverty, homelessness, substance misuse and living in residential settings further increase the risk of poorer outcomes among people with SMI, in the case of exposure to COVID-19 (Thornicroft et al. 2009; Green et al. 2018).

As a direct result of the need to reduce transmission of COVID-19 by implementing social (or physical) distancing, many patients attending mental health services have had reduced access to their usual face-to-face mental 
health supports. Mitigation strategies have necessitated the closure of day hospitals, day centres, treatment groups such as dialectical behavioural therapy and routine faceto-face contact with members of the community mental health team. In many cases, the usual face-to-face contact has been replaced with telephone or video contact. In China, similar limitations placed on mental health services by COVID-19 were associated with relapse of pre-existing mental illness (Yang et al. 2020).

Internationally, concerns have been raised regarding the potential impact of social (or physical) distancing on the mental health of populations both with and without pre-existing mental illnesses (Galea et al. 2020; Venkatesh \& Edirappuli, 2020). Specifically, factors including social (or physical) distancing, reduced access to social supports, physical illness and barriers to mental health treatments were together predicted to reduce the resilience of the population overall and potentially increase the risk of suicide (Reger et al. 2020). In addition, it has been posited that increased alcohol consumption, domestic violence and economic sequelae of the COVID-19-related restrictions may contribute to heightened risk of suicidal behaviours (Gunnell et al. 2020).

The SARS outbreak in 2003 was followed by a peak in suicides among older adults in Hong Kong (Chan et al. 2006). It was associated with increased rates of stress, distress, anxiety disorders including posttraumatic stress disorder, and depressive illnesses (Lee et al. 2007; Mak et al. 2009). Given the similarities with COVID-19, a risk of similar population increases in depressed mood, anxiety and suicidal thoughts was predicted in response to the 2020 COVID-19 pandemic (Torales et al. 2020). The reductions in normal social interactions and activities and resulting social isolation may potentiate these difficulties, given that in addition to being important for wellbeing, these are also protective against suicide (Zadravec Šedivy et al. 2017).

There were real concerns about the practical management of mental health crises, due to the combination of reduced face-to-face supports and increased social isolation (Yao et al. 2020). In addition, the restrictions in visiting hospitals and changes to emergency pathways might deter people from attending hospital when needed in a crisis. Locally, in Galway, an alternative pathway for the management of mental health crises was developed to allow for the safe assessment of people with mental disorders presenting acutely, away from the COVID-19 pathway.

Self-harm is an important predictors of suicide and as such represents an important opportunity to intervene (Carroll et al. 2014; Bostwick et al. 2016). There is little published regarding self-harm in relation to COVID-19: internationally, there have been three cases attributed to COVID-19 in case reports from India and Germany (Sahoo et al. 2020; Weise et al. 2020).

This paper aims to assess the impact of COVID-19 and the associated social change on rates of self-harm at a tertiary university hospital in Ireland, by comparing the levels of self-harm during the periods of the pandemic with the same months and weeks in three previous years: 2017, 2018 and 2019. It aims to examine the methods and severity of self-harm and suicidal behaviours, and the associated diagnoses and treatments.

\section{Method}

The Liaison Psychiatry Team (LPT) at University Hospital Galway (UHG) maintains a database of all patients who are referred for assessment by the service, both within the working hours of the team and out of hours. UHG is a tertiary university hospital on the west coast, with 850 beds over 2 sites. It is the only Model 4 hospital in the Saolta Group and as such receives complex specialty referrals from the other group hospitals, some of which are over $200 \mathrm{~km}$ distant. These include urgent referrals to plastic surgery in the case of severe self-lacerations requiring surgical intervention. The LPT is a team of psychiatrists and mental health nurses which provides psychiatric consultations and treatments to patients admitted to medical and surgical wards and those attending the emergency department (ED). In 2020 during the study period, it was staffed at under $30 \%$ of national and international standards (DoH, 2006; PLAN, 2014).

The service database includes patients referred from the ED, the medical and surgical wards, and the critical care unit. It includes basic demographic and clinical information, including age, gender, reason for referral, diagnosis, and treatments including whether or not the person is admitted to the acute adult mental health inpatient unit. Information was extracted on patients referred to the service with self-harm in the 3 months at the height of the pandemic: 1 March to 31 May 2020. These were compared to the referrals received from 1 March to 31 May in the three preceding years: 2017, 2018 and 2019.

Self-harm was defined as per the WHO as 'an act with non-fatal outcome, in which an individual deliberately initiates a non-habitual behaviour that, without intervention from others, will cause self-harm, or deliberately ingests a substance in excess of the prescribed or generally recognised therapeutic dosage, and which is aimed at realising changes which the subject desired via the actual or expected physical consequences' (Platt et al. 1992).

We used source of referral as a surrogate for severity of self-harm: we categorised those requiring admission to critical care as the most severe (these patients would likely have died without treatment); those requiring 


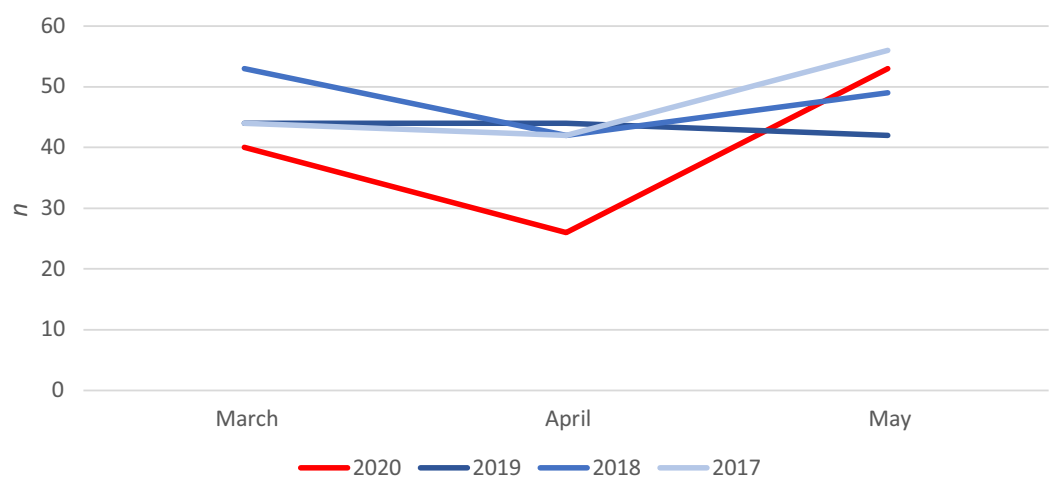

Fig. 1. Self-harm presentations by month March-May over 4 years 2017-2020.

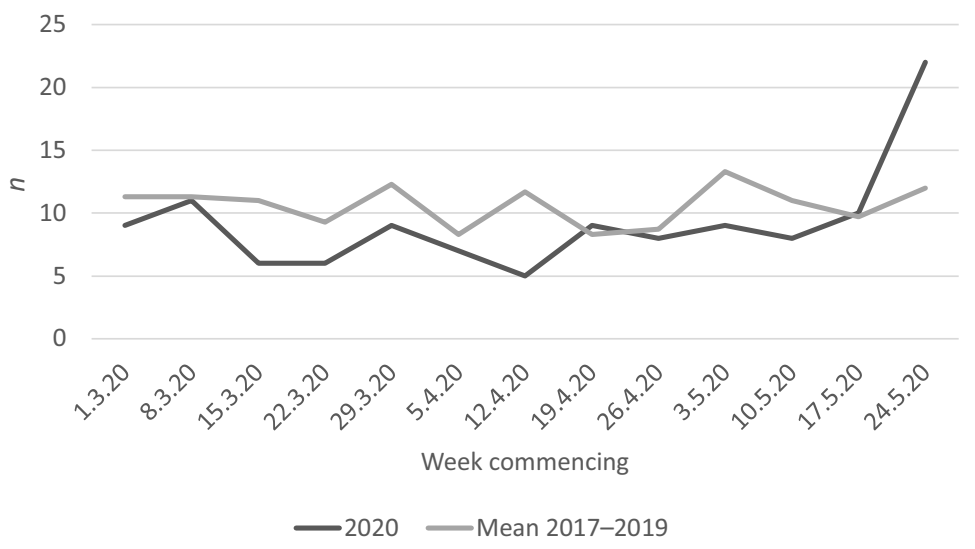

Fig. 2. Self-harm presentations by week March-May compared with mean 2017-2019.

medical or surgical admission were moderately severe as the toxicity or injuries inflicted required inpatient treatments; and those who could be discharged home from the ED or equivalent were the least severe as they did not require inpatient medical treatment. This measure gives an approximation of lethality, although it was not possible to capture the degree of suicidal intent from the database.

For the purpose of this study, the anonymised data were exported to an SPSS file. Given the changing nature of the restrictions over time, data were broken down by month and week for 2020. Chi-square was used to compare the categorical variables, and independent sample $t$-test was used to compare the scale variables. We used a logistic regression model to control for age and gender.

Ethical approval was obtained from the Clinical Research Ethics Committee of the Saolta Hospital Group (no. 2386). As all data were anonymised, written consent was not required.

\section{Results}

From 1 March to 31 May 2020, there were 576 referrals to psychiatry compared with 760 in the same months in
2019: an overall reduction of $31.9 \%$. From 1 March to 31 May 2020, there were 119 referrals with self-harm compared with 130 in the same months in 2019: a reduction of $8.5 \%$ : the decrease in presentations with self-harm was less than the decrease in attendances for other psychiatric indications. In 2020, the rate of presentation with self-harm dropped by 35\% from March to April but rose by $104 \%$ from April to May (Fig. 1). The degree of variability week to week was considerable, but throughout the first 10 weeks of COVID-19 the rates remained constant (range 5-11/week), with a precipitous increase from mid-May (Fig. 2).

Table 1 describes the characteristics of those patients who were referred for a psychiatric assessment with self-harm. There were no significant differences in the age or gender of patients referred in 2020 compared with previous years.

There were significant differences in source of referral (i.e. from the ED, inpatient wards or critical care) a proxy for lethality $(p<0.001)$ with a significant increase in numbers of patients requiring medical or surgical admission for management of their self-injury or poisoning; from $8.9 \%$ to $24.4 \%$ of patients presenting with self-harm (2.7-fold). There were no significant changes in method of self-harm, although there were trend 
Table 1. Demographic and clinical characteristics of patients presenting to the emergency department with self-harm in the 3 months of the 2020 COVID-19 crisis, compared with those presenting in the preceding 3 years

\begin{tabular}{|c|c|c|c|}
\hline & $2020(n=119)$ & 2017-2019 $(n=406)$ & $p$-Value \\
\hline \multicolumn{4}{|l|}{ Gender } \\
\hline Female, $n(\%)$ & $68(57.1)$ & $254(61.1)$ & \multirow[t]{2}{*}{$0.442^{\mathrm{a}}$} \\
\hline Male, $n(\%)$ & $51(42.9)$ & $162(38.9)$ & \\
\hline Age, mean (SD) & $34.1(15.8)$ & $31.6(15.1)$ & $0.106^{\mathrm{b}}$ \\
\hline \multicolumn{4}{|l|}{ Age } \\
\hline$<18$ years, $n(\%)$ & $18(15.1)$ & $73(17.5)$ & \multirow[t]{3}{*}{$0.668^{\mathrm{a}}$} \\
\hline $18-64$ years, $n(\%)$ & $94(79)$ & $325(78.1)$ & \\
\hline$>65$ years, $n(\%)$ & $7(5.9)$ & $18(4.3)$ & \\
\hline \multicolumn{4}{|l|}{ Source of referral } \\
\hline Emergency department, $n(\%)$ & $84(70.6)$ & $355(85.3)$ & \multirow[t]{3}{*}{$<0.001^{\mathrm{a}}$} \\
\hline Medical/surgical wards, $n(\%)$ & $29(24.4)$ & $37(8.9)$ & \\
\hline Critical care, $n(\%)$ & $6(5)$ & $24(5.8)$ & \\
\hline \multicolumn{4}{|l|}{ Method of self-harm } \\
\hline Poisoning, $n(\%)$ & $85(71.4)$ & $188(61.6)$ & \multirow[t]{5}{*}{$0.069^{\mathrm{a}}$} \\
\hline Cutting, $n(\%)$ & $20(16.8)$ & $71(23.3)$ & \\
\hline Drowning, $n(\%)$ & $1(0.8)$ & $17(5.6)$ & \\
\hline Hanging, $n(\%)$ & $5(4.2)$ & $16(5.2)$ & \\
\hline Other, $n(\%)$ & $8(6.7)$ & $13(4.3)$ & \\
\hline \multicolumn{4}{|l|}{ Diagnosis } \\
\hline Depressive episode, $n(\%)$ & $22(18.6)$ & $91(22.8)$ & \multirow[t]{7}{*}{$0.031^{\mathrm{a}}$} \\
\hline Adjustment disorder, $n(\%)$ & $20(16.9)$ & $54(13.5)$ & \\
\hline Personality disorder, $n(\%)$ & $18(15.3)$ & $79(19.8)$ & \\
\hline Substance misuse, $n(\%)$ & $36(30.5)$ & $87(21.8)$ & \\
\hline Anxiety disorders, $n(\%)$ & $8(6.8)$ & $19(4.8)$ & \\
\hline SMI (psychosis and BPAD), $n(\%)$ & $10(8.5)$ & $22(5.5)$ & \\
\hline Other & $4(3.4)$ & $47(11.8)$ & \\
\hline \multicolumn{4}{|l|}{ Treatment plan } \\
\hline Admission, $n(\%)$ & $18(15.1)$ & $73(17.5)$ & \multirow[t]{4}{*}{$0.46^{\mathrm{a}}$} \\
\hline CMHT, $n(\%)$ & $90(75.6)$ & $298(71.6)$ & \\
\hline Addictions, $n(\%)$ & $3(2.5)$ & $23(5.5)$ & \\
\hline Primary care, $n(\%)$ & $8(6.7)$ & $22(5.3)$ & \\
\hline
\end{tabular}

SMI, severe mental illness; BPAD, bipolar affective disorder; CMHT, community mental health team. ${ }^{a}$ Chi-square.

bIndependent sample $t$-test.

increases in self-poisoning and trend reductions in cutting.

There were significant differences in the underlying diagnoses - in particular, an increase in primary substance misuse presentations: from $21.8 \%$ to $30.5 \%$ $(p=0.031)$. There was a trend increase in people with a diagnosis of SMI presenting with self-harm: from $5.5 \%$ to $8.5 \%$. There was a trend increase in the proportion of people with adjustment disorders and with anxiety disorders, and a decrease in those with depressive episodes and with personality disorders.

There were no significant differences in treatment between the stude period and the comparison periods in the previous 3 years. Rates of psychiatric admissions of people presenting with self-harm dropped from
$17.5 \%$ to $15.1 \%$, but this change was not statistically significant.

On logistic regression, after controlling for age and gender, the differences in severity or medical lethality of self-harm remained significant between 2020 and previous years (OR 1.47; $p=0.036$; 95\% CI 1.023-20.72), that is, there was a significant increase in patients requiring medical admission for treatment (Table 2). The differences in diagnosis also remained significant (OR 1.38; $p=0.018 ; 95 \%$ CI 1.236-17.78).

\section{Discussion}

This study shows that there was a small overall reduction of $8.5 \%$ in the numbers of patients presenting 
Table 2. Logistic regression with year (2020 v. earlier years) as the dependent variable

\begin{tabular}{lccc}
\hline & $\begin{array}{c}\text { Odds } \\
\text { ratio }\end{array}$ & $p$-Value & $95 \%$ CI \\
\hline Gender & 0.893 & 0.596 & $0.587-1.358$ \\
Age & 1.007 & 0.332 & $0.983-1.020$ \\
$\begin{array}{l}\text { Source of referral/severity } \\
\quad \text { of self-harm }\end{array}$ & 1.46 & 0.037 & $1.023-2.072$ \\
\hline
\end{tabular}

${ }^{a}$ Referral source was used as a surrogate measure for severity, with referrals from critical care most severe, patients who required medical or surgical admission considered moderately severe, and those not requiring inpatient treatment considered least severe.

with self-harm from 1 March to 31 May 2020, compared with the same period in 2019. When trends over a 4-year period were examined, there were no significant changes in the patterns of age or gender in those presenting with self-harm in 2020 compared with previous years. There was a significant increase in the lethality of presentations reported and this remained significant after age and gender were controlled for. There were significant differences in the underlying psychiatric diagnoses, notably a significant increase in substance misuse disorders and SMI.

This study reported low levels of self-harm during the month of April, particularly in the week of 12 April, which was the month and week where Ireland recorded the highest number of COVID-19 cases throughout the period of the outbreak (CovidwatchIrl, 2020; DoH, 2020). It is possible that people who are at risk or may have self-harmed may not have sought medical attention in the hospital setting if they perceived that the self-harm was not severe enough as to require immediate medical attention, due to the severity of the pandemic in the country at that time. Fear among the public about attending hospital during the lockdown dissuaded many with serious or potentially life-threatening conditions from seeking medical care, including those with strokes and acute coronary syndromes (Kristoffersen et al. 2020; Mafham et al. 2020). During the early stages of the lockdown, it is possible that only those with the most severe self-harm attended hospital. In May, the steep increase in the number of cases of self-harm coincides with the easing of restrictions in the country, with Phase 1 of easing of the lockdown beginning on 18 May (DoH, 2020). It is likely that as people become more relaxed about COVID-19, the public is more willing to present to the hospital for help with non-COVID-19-related conditions, including self-harm. Another reason for the sharp rise could be the aftermath of a national lockdown, with cocooning for the high-risk population.

Previous viral epidemics have been accompanied by peaks in rates of suicide: this was first reported following the 1918 'Spanish' influenza pandemic in the US (Wasserman, 1992), and more recently following the SARS outbreak in Hong Kong (Chan et al. 2006). Like in the case of the SARS outbreak in 2003, this study provides early evidence that the COVID-19 outbreak may be associated with increased rates of anxiety disorders and with increased severity of self-harm and suicidal behaviours (Chan et al. 2006). There is little published on any relationship which may exist between COVID-19 and self-harm, with three cases attributed to its societal sequelae reported from India and Germany (Sahoo et al. 2020; Weise et al. 2020). The two cases from India appear to have been of depressive episodes triggered by health anxiety, and the case in Germany related to a delusional disorder: none of the three patients described had any psychiatric history. Similarly, in this study, there were increased rates of patients presenting with self-harm on a background of anxiety disorders and psychotic illnesses. In this study, the association of self-harm with a primary diagnosis of substance misuse disorders is of concern and may reflect an increase in alcohol consumption in the general population.

People with self-harm with more serious injuries or poisoning require a medical or surgical admission, and the most gravely ill with a life-threatening status may require treatment in the critical care unit. This range of presentations may be regarded as a spectrum of lethality, with suicidal ideation at one end and completed suicide at the other (Mohan et al. 2020). This conceptualisation of lethality suggests that patients who require critical care interventions may be more similar to those who die by suicide, than those requiring brief review only. It is unclear to what degree suicidal intent is associated with suicidal lethality.

Regarding future trends, the economic fallout of the crisis will be important. There is evidence that economic crises are associated with poorer mental health outcomes and increased rates of suicides with evidence that every $1 \%$ increase in unemployment is associated with a $0.79 \%$ increase in rates of suicide (Stuckler et al. 2009). In March 2020, the International Labour Organization estimated that global employment would decline by between 5.3 and 24.7 million (I.L.O., 2020). Based on these projected figures of unemployment as a result of COVID-19, it is predicted that there would be a rise of between 2135 and 9570 suicides per year (Kawohl \& Nordt, 2020), from the base level of nearly 800000 suicides annually (WHO, 2019a). This figure does not account for episodes of self-harm which is postulated to be increasing. According to $\mathrm{WHO}$, for every suicide, there are over 20 suicide attempts (WHO, 2019b), and existing research has shown that self-harm and suicidal behaviour is a strong risk factor 
for death by suicide (Carroll et al. 2014; Bostwick et al. 2016).

The limitations of this study include its retrospective design and its basis on a service database which outruled the incorporation of patient-reported measures. The use of a database might also be considered to be a strength, as all patients presenting with self-harm were included, removing participation or selection bias. In the absence of a patient-reported measure of intent or perceived lethality, the degree of medical support required provides a surrogate marker of severity.

This is the first study to examine variations in rates of self-harm associated with the COVID-19 pandemic in 2020, and it provides early evidence that there may be changes in rates of self-harm associated with the crisis.

There is a need for further research into the longerterm effect of the restrictions and changes due to COVID-19 over the months ahead. If a period of economic instability follows as predicted, this may have a further impact on the mental health of the population, and perhaps on rates of self-harm.

\section{Conclusion}

COVID-19 showed a reduction in self-harm presentations initially, followed by a sharp increase in May 2020. If a period of economic instability follows as predicted, it is likely that this will further impact the mental health of the population, along with rates of self-harm. There is a need for research into the longer-term effect of the restrictions and changes due to COVID-19 on mental health, mental illness and suicidality. There is evidence of the need for mitigation measures to ensure psychiatric services are adequately resourced to provide a high standard of care for those who require it.

\section{Financial support}

This research received no specific grant from any funding agency, commercial or not-for-profit sectors.

\section{Conflict of interest}

Authors [MA, TK, ME and DAM] have no conflicts of interest to report.

\section{Ethical standards}

The authors assert that all procedures contributing to this work comply with the ethical standards of the relevant national and institutional committee on human experimentation with the Helsinki Declaration of 1975, as revised in 2008. The study protocol was approved by the Clinical Research Ethics Committee of the Saolta Hospital Group (no. 2386).

\section{References}

Bostwick JM, Pabbati C, Geske JR, McKean AJ (2016). Suicide attempt as a risk factor for completed suicide: even more lethal than we knew. American Journal of Psychiatry 173, 1094-1100.

Carroll R, Metcalfe C, Gunnell D (2014). Hospital presenting self-harm and risk of fatal and non-fatal repetition: systematic review and meta-analysis. PLoS One 9, e89944.

Chan SM, Chiu FK, Lam CW, Leung PY, Conwell Y (2006). Elderly suicide and the 2003 SARS epidemic in Hong Kong. International Journal of Geriatric Psychiatry 21, 113-118.

Chesney E, Goodwin GM, Fazel, S (2014). Risks of all-cause and suicide mortality in mental disorders: a meta-review. World Psychiatry 13, 153-160.

CovidwatchIrl (2020). Covidwatch Cases and Deaths. University of Limerick: Limerick, Ireland.

DoH (2006). A Vision for Change. Report of the Expert Group on Mental Health Policy. DoH: Dublin.

DoH (2020). Updates on COVID-19 (Coronavirus) from April - June 2020. Department of Health: Dublin.

Fok ML, Hayes RD, Chang CK, Stewart R, Callard FJ, Moran P (2012). Life expectancy at birth and all-cause mortality among people with personality disorder. Journal of Psychosomatic Research 73, 104-107.

Galea S, Merchant RM, Lurie N (2020). The mental health consequences of COVID-19 and physical distancing: the need for prevention and early intervention. JAMA Internal Medicine 180, 817-818.

Green MF, Horan WP, Lee J, McCleery A, Reddy LF, Wynn JK (2018). Social disconnection in schizophrenia and the general community. Schizophrenia Bulletin 44, 242-249.

Gunnell D, Appleby L, Arensman E, Hawton K, John A, Kapur N, Khan M, O'Connor RC, Pirkis J (2020). Suicide risk and prevention during the COVID-19 pandemic. Lancet Psychiatry 7, 468-471.

I.L.O. (2020). Almost 25 Million Jobs Could Be Lost Worldwide as a Result of COVID-19, Says ILO. International Labour Organization.

Kawohl W, Nordt C (2020). COVID-19, unemployment, and suicide. Lancet Psychiatry 7, 389-390.

Kozloff N, Mulsant BH, Stergiopoulos V, Voineskos AN (2020). The COVID-19 global pandemic: implications for people with schizophrenia and related disorders. Schizophrenia Bulletin 46, 752-757.

Kristoffersen ES, Jahr SH, Thommessen B, Rønning OM (2020). Effect of COVID-19 pandemic on stroke admission rates in a Norwegian population. Acta Neurologica Scandinavica. doi: 10.1111/ane.13307. Online ahead of print.

Lee AM, Wong JG, McAlonan GM, Cheung V, Cheung C, Sham PC, Chu CM, Wong PC, Tsang KW, Chua SE (2007). Stress and psychological distress among SARS survivors 1 year after the outbreak. Canadian Journal of Psychiatry 52, 233-240.

Mafham MM, Spata E, Goldacre R, Gair D, Curnow P, Bray M, Hollings S, Roebuck C, Gale CP, Mamas MA, 
Deanfield JE, de Belder MA, Luescher TF, Denwood T, Landray MJ, Emberson JR, Collins R, Morris EJA, Casadei B, Baigent C (2020). COVID-19 pandemic and admission rates for and management of acute coronary syndromes in England. Lancet 396, 381-389.

Maguire PA, Reay RE, Looi JC (2019). Nothing to sneeze at - uptake of protective measures against an influenza pandemic by people with schizophrenia: willingness and perceived barriers. Australasian Psychiatry 27, 171-178.

Mak IW, Chu CM, Pan PC, Yiu MG, Chan VL (2009). Long-term psychiatric morbidities among SARS survivors. General Hospital Psychiatry 31, 318-326.

Mohan C, Tembo V, McNicholas B, Doherty AM (2020). Defining high risk by clinical lethality: the different characteristics and management of the survivors of serious self-injury admitted to critical care, compared with lower lethality self-injury. General Hospital Psychiatry 64, 131-132.

PLAN (2014). Quality Standards for Liaison Psychiatry Services. Royal College of Psychiatrists; Royal College of Physicians; Royal College of Nursing; the College of Emergency Medicine. London.

Platt S, Bille-Brahe U, Kerkhof A, Schmidtke A, Bjerke T, Crepet $\mathbf{P}$, et al. (1992). Parasuicide in Europe: the WHO/ EURO multicentre study on parasuicide. I. Introduction and preliminary analysis for 1989. Acta Psychiatrica Scandinavica 85, 97-104.

Prince M, Patel V, Saxena S, Maj M, Maselko J, Phillips MR, Rahman A (2007). No health without mental health. Lancet 370, 859-877.

Reger MA, Stanley IH, Joiner TE (2020). Suicide mortality and Coronavirus disease 2019-a perfect storm? JAMA Psychiatry. Published online April 10, 2020. doi:10.1001/ jamapsychiatry.2020.1060

Rogers JP, Chesney E, Oliver D, Pollak TA, McGuire P, Fusar-Poli P, Zandi MS, Lewis G, David AS (2020). Psychiatric and neuropsychiatric presentations associated with severe coronavirus infections: a systematic review and meta-analysis with comparison to the COVID-19 pandemic. Lancet Psychiatry 7, 611-627. doi: 10.1016/ S2215-0366(20)30203-0

Sahoo S, Rani S, Parveen S, Pal Singh A, Mehra A, Chakrabarti S, Grover S, Tandup C (2020). Self-harm and COVID-19 pandemic: an emerging concern - a report of 2 cases from India. Asian Journal of Psychiatry 51, 102104

Stuckler D, Basu S, Suhrcke M, Coutts A, McKee M (2009). The public health effect of economic crises and alternative policy responses in Europe: an empirical analysis. Lancet 374, 315-323.

Thornicroft G, Brohan E, Rose D, Sartorius N, Leese M (2009). Global pattern of experienced and anticipated discrimination against people with schizophrenia: a crosssectional survey. Lancet 373, 408-415.

Torales J, O'Higgins M, Castaldelli-Maia JM, Ventriglio A (2020). The outbreak of COVID-19 coronavirus and its impact on global mental health. International Journal of Social Psychiatry 66, 317-320.

Venkatesh A, Edirappuli S (2020). Social distancing in covid-19: what are the mental health implications? Bmj 369, $\mathrm{m} 1379$.

Walker ER, McGee RE, Druss BG (2015). Mortality in mental disorders and global disease burden implications: a systematic review and meta-analysis. JAMA Psychiatry 72, 334-341.

Wasserman IM (1992). The impact of epidemic, war, prohibition and media on suicide: United States, 1910-1920. Suicide and Life-Threatening Behavior 22, 240-254.

Weise J, Schomerus G, Speerforck S (2020). The SARSCoV-2 pandemic and an attempted suicide of a patient with delusional disorder. Psychiatrische Praxis 47, 218-220.

WHO (2019a). Suicide. World Health Organization: Geneva.

WHO (2019b). Suicide Prevention. World Health Organisation: Geneva.

Yang Y, Li W, Zhang Q, Zhang L, Cheung T, Xiang YT (2020). Mental health services for older adults in China during the COVID-19 outbreak. Lancet Psychiatry 7, e19.

Yao H, Chen JH, Xu YF (2020). Patients with mental health disorders in the COVID-19 epidemic. Lancet Psychiatry 7, e21.

Zadravec Šedivy N, Podlogar T, Kerr DCR, De Leo D (2017). Community social support as a protective factor against suicide: A gender-specific ecological study of 75 regions of 23 European countries. Health Place 48, $40-46$. 